\title{
The Notebook to Reflect on the Meaning of Life: A Page Inside the ePortfolio
}

\author{
Concetta La Rocca, Massimo Margottini ${ }^{1}$ \\ Department of Eduactions, Roma Tre University, Rome, Italy
}

*Corresponding Author: Concetta La Rocca, Department of Eduactions, Roma Tre University, Rome, Italy

\begin{abstract}
In this study we support the need to provide subjects with useful tools for the overall reflection on their own path in order to help them become more aware of their strengths and weaknesses and therefore to draw a line of conduct on which they can imagine and build a future in field of existenzial dimension, training, work, relationship. The ePortfolio is an appropriate tool to design future starting from reflection on past experiences and from the analysis of the present. The authors, already in previous researches, have built an ePortfolio considering it a semi-structured tool/environment because subjects freely build some pages and compile structured tools for the construction of other pages. This study presents one of these structured tools called Notebook for the reflection on the meaning of life which constitutes, precisely, a page of eP; the notebook allows you to accompany the subject to reflect on the meaning of her/his life path using the imagination and the dimension of values. The Notebook is ongoing in empirical experimentation in some upper classes of "Einaudi Professional Institute” in Rome.
\end{abstract}

Keywords: Holistic Orientation; Reflection; Transformation; Values; Meaning of Life

\section{INTRODUCTION}

Contemporary society often faces dilemmas concerning the formative and the working path. Particularly in this work we analyze the dilemma trainers have in regard to guidance. To guide means: A) analyzing skills possessed by the subject to help him find the most appropriate profession?; or: B) supporting the subject in the self-analysis of her/his training path in order to bring out the authentic motivational drive to implement behaviors that give meaning to her/his existence in an overall way? Naturally, the search for employment is always of primary importance, but, in the second alternative, it is not considered exclusive and exhaustive of the orientation. The issue is even more problematic if the goal is to facilitate the inclusion of young/adult migrants, first and second generation, in schools and working environments, trying them to bring out not only their skills and knowledge, but also their desires, passions and visions of the world. To this purpose, an operational/theoretical model has been developed regarding the educational training and professional orientation within the framework of the CREI Project - Creating Networks for Immigrants; in italian: CreareREti per Immigranti $-^{2}$.Starting from the assumption of the themes related to the transformative learning and to the productive value of the crisis experience (Mezirow 1999), in this study we support the need to provide subjects with useful tools for the overall reflection on their own path in order to help them become more aware of their strengths and weaknesses and therefore to draw a line of conduct on which they can imagine and build an educational, existential, formative, working and social future (Batini 2005, Bruner, 1992).The ePortfolio (electronic portfolio on web platform) (Barrett 2000, 2003; Huang et al 2012; La Rocca 2015; Pitts et al 2012) is an appropriate tool to design one's future starting from a reflection on past experiences and from the analysis of the present (Margottini, 2017). The authors, already in

\footnotetext{
${ }^{1}$ The ideation of the work is due to both authors; the writing of the whole text is by Concetta La Rocca.

${ }^{2}$ The Project is coordinated by Prof. Massimo Margottini, Dept. of Education Sciences, Roma Tre University. It was funded by the Ministry of the Interior (Asylum Fund, Migration and Integration 2014) and had the aim of contributing to the qualification of the system of public and private institutions, in the XIV Municipality of Rome, for the protection of non-EU minors and young people citizens.
} 
previous researches, have built an ePortfolio considering it a semi-structured tool/environment because subjects build freely some ePpages and build other pages using systematic indications provided by the teacher. This study presents the systematic indications that constitute the Notebook for the reflection on the meaning of life which allows the subject to reflect on the meaning of her/his life path using the imagination (Mancinelli, 2008) and the dimension of values (Bernaud, 2015). As we said, the Notebook was born within the CREI Project, anditis being tested in the EINAUDI Professional Institute which has joined the project and whose student population is mostly composed of young people with problems (foreigners, various difficulties....); anyway it can be considered a useful tool for young adults to enhance the exercise of reflection as a valid reference in transitional moments. Of course, the compilation of the Notebook involves the interaction with an expert who supports the subject in the drawing up because the reflection is certainly facilitated in the dialectical and interlocutory relation. This work presents the framework of theoretical reflections in which Notebook is inserted and the justification of its conception.

\subsection{The Question}

Nowadays the activities of orientation to training and work must take into account the problems and contradictions of our complex contemporary society. Therefore the deterministic conceptions of the orientation - that substantially provided for the adaptation of the subject to a stable social and working reality - can be considered superseded. Today it is preferable to have a vision of the orientation that develops in the people the ability to interact actively with the social context, maintaining firm decision-making on a wide-ranging life project but at the same time assuming forms of flexibility, adaptability, initiative and planning (Guichard\&Huteau, 2001).In fact the functionalistic theories/practices might be considered unsuitable to the times because they aim to build a consecutive relationship between (the) school and (the) working life to promote stable employment and because they are essentially aimed at achieving only educational success to reduce early school leaving. Now we prefer to have an holistic perspectives that place the person at the center of his/her orientative project, in which he/she is capable of self-orientation in a dynamic socio-economic-cultural context and sometimes so unstable as to generate what Guichrad (2001) defines vocational chaos. The ability to cope with sudden and radical changes (Mezirow, 2003) imposes the need to stop and reflect especially when the personal situations are such problematic that require taking positions to determine a change and to enable people to actualize the personal potential sense of life. Therefore, adults today must possess many of the transversal/soft skills, that EU believes necessary in the young training process (Pellerey, 2007); this means that if our society de facto requires adults to be ready to face sudden changes in employment and social status, obviously the same society will have to ensure the same adults to possess the necessary skills to cope with the problematic situations that could arise. Educators should take, among their training goals, the development of guidance skills in children (future adults), for example: the ability to plan actions and put them into practice; the ability to be aware of their own cognitive and decisional processes; the ability to relate positively with others; the ability to keep their own existential values. So, in short, teachers should educate children to selforientation, so that they can reach the decision-making autonomy that allows them to place themselves as a stable center in a world that swirls, drawing on knowledge and skills that are deep, stable, systematic and structured (Domenici, 2009).It is urgent to activate a holistic orientation in our schools because classes, daily attended by children, have high percentages of students with special needs, with cognitive and behavioral disorders or coming from family or social situations characterized by educational poverty or from emergency situations, also politics (young immigrants).In order to intervene in problematic school contexts by adopting a holistic orientation, the hypothesis was formulated that, among the various educational measures aimed at developing the aforementioned skills, the use of structured guidelines could be effective to stimulate forms of reflection and reasoning about elements that belong to the profound sphere of people's feelings, what the values and the attribution of meaning to one's own life are. The elaboration of these structured guidelines was carried out within the CREI Project, which will be summarized in the next paragraph; but it is believed that the structured guidelines, taken into account in this work, or the Notebook to reflect on the Sense of Life, can potentially be used in various training contexts (reception centers for migration, adults education centers, schools, employment centers, etc). 


\section{CREI PROJECT}

The CREI Project is coordinated by Prof. Massimo Margottini, Dept. of Education Sciences, Roma Tre University ${ }^{3}$. It was funded by the Ministry of the Interior (Asylum Fund, Migration and Integration 2014) and had the aim of contributing to the qualification of the system of public and private institutions, in the XIV Municipality of Rome, for the protection of non-EU minors and young people citizens. It has been structured on three main lines: 1. Educational, training and professional orientation 2. Social inclusion 3. Protection. The general objective of the project was to carry out a capacity building action, aimed at enhancing the capacity of all the players operating on the ground, encouraging: the consolidation of active networks and the creation of new networks; the sharing of good practices and methodologies of intervention; the starting of a participatory planning phase for the elaboration of effective methods of taking charge and of support to young people and minors for paths of full inclusion. The project has paid particular attention to educational, training and work orientation, fundamental to counter the risks of hardship and discrimination, through an action that can improve the single service, the connection between the various services and the building of the whole system. (an extract from the text of the project). In particular, the perspective developed within the main line for the Orientation has strongly emphasized the need to promote individualized educational processes using a modular and flexible didactics to enhance the specific individual differences (cultural, cognitive, etc) in order to harness potential that will enable them to create their own development. In the project was elaborate a model/protocol to reception the foreign youngadults; it was called the booklet/portfolio and it was considered appropriate to develop, in the same, a dedicated section/page to the reflection about values and the meaning of life, in addition to the more usual dimensions related to professional skills possessed by the subjects. In fact, in the theoretical project framework, a main principle has been elaborated: the action to guide young immigrants cannot be reduced to the exclusive objective of identifying any possessed professional skills in order to facilitate their integration into the working life, but should aim to bring out their desires and projects, expectations and interests. Of course it was not a naive vision that did not take into account the actual physical, mental and cultural status of young people who have had extreme and often devastating experiences, but we wanted to try not to crush them in this image, although absolutely real, but sometimes bringer of a sort of prejudice / stereotype on the figure of the migrant. It was decided to try to urge in them a reflection on themes concerning their overall vision about the meaning of life, and, in particular, about the meaning attributed to their own life.The work of investigation, reflection and revision of the various sections of the tool (Notebook to reflect on the Sense of Life) was shared between university researchers and teachers/educators who work within the training structures involved in the project.

\subsection{The Notebook to Reflect on the Sense of Life: Theories}

The conceptual framework, to which this work refers, places the theme of reflection as a pivotal element from which to develop in boys and young adults those meta cognitive skills that can enable them to become conscious and protagonists of their own path of educational and professional growth (Pellerey, 2004; 2007).The importance of reflection in the educational field is strongly emphasized by Dewey (1938), who notes that it is not experience but reflection on experience that significantly changes the convictions of a subject and therefore produces a cognitive modification, such a learning. Mezirow (1999), Bernaud (2015) and Mancinelli (2008), who are the authors referred to more explicitly for the theoretical elaboration of the Notebook on the Meaning of Life, underline the importance of reflection, as a key concept, to drive a subject to critically analyze his own convictions and to reformulate the justification process that sustains them; the authors also highlight how appropriate it is to educate the subject in the development of soft skills that allow to acquire that flexibility, in their thought and in their action, absolutely necessary to face the specific and complex contexts of current life. It must be stressed/ focused, however, that the general objective of education for reflection is not at all to offer certainties and teleological perspectives, oriented towards a resolution of socially and culturally accepted problems and considered "true" and "just", but the aim of the reflection is to induce the subject to reconsider his/her convictions starting from the provocations that life contexts place in front of him/ her. The task of the educator is to facilitate a

3 Partner of the Project: Cooperativa Sociale "Apriti Sesamo" di Roma; Centro Provinciale Istruzione degli Adulti (CPIA 3) di Roma; Opera Don Calabria di Roma; Istituto Psicoanalitico per le Ricerche Sociali (IPRS) di Roma. 
process of elaboration in which posing problems and trying to solve them, certainly not that of leading the subject to a predefined goal. In fact, Mezirow (1999) says that "Transformative learning is learning to see through one's experience to discover what has been taken-for-granted"; transformative learning is not a movement that proceeds from what is false towards what is true, but rather it is the transition from an uncritical belief to one that is justified by empirical experiences or by continuous processes of reasoning. Mezirow emphasizes that the theory of transformative learning, although born in the Western world, develops through the solicitation of a critical thought that can challenge even the cultural pillars of our own Western world because its goal is to make each member subject of a community of speakers, with and through whom formulate and reformulate strategies of selfmotivation and self-direction.

Every culture has its own meta-narratives that are great shared paradigms of reading and interpreting reality; transformative learning is not interesting in the question about the meaning of these great narratives, but its interest is directed to the search for critical questions on their foundations. Of course, the educational goal is not to silence fundamental questions but to promote the development of dubious and of rational thinking that continues to pose /cause problems and seek answers, in a sort of maieutic research about the meaning of life and about the things that can be done in life. In one's own life and in the life of the community.

And it is precisely at this point of Mezirow's reasoning that it seems possible to insert the perspective, elaborated by Bernaud, that concerns the search for the meaning of life and work. Bernaud (2015) affirms that "if the meaning of life is such a central element, this does not depend on theoretical or ideological reasons" and citing several empirical studies, considers that "a low level of meaning in life has long been considered as a factor capable of causing crisis, malaise / discomfort, and even a feeling of despair. (...) On the contrary, the fact of having found a sense of life is a factor of resistance to extreme situations, as Frankl demonstrated with regard to the survival of deportees in death camps ${ }^{\prime 4}$.The concept of the meaning of life is complex and full of religious, philosophical and cultural influences, but this does not mean that it cannot be operationalized, or incorporated into a model that can be applied concretely to the real life contexts. The purpose of the application of such a model is certainly not to solve sic et simpliciter the existential dimension of a subject, but it is that to promote a training for the reflection and the reformulation of projects and perspectives, thus because the development of the meaning of life, one's life, can be a useful strength element even in difficult situations, "a factor of protection and adaptation both in personal and in professional life"

The construction of the meaning of life is in fact a perpetual motion that has no end and that accompanies the subject throughout his /her existence since "it is based primarily on the analysis and interpretation of lived experiences that lead everyone to elaborate some aspects of one's (own) identity, to actualize one's personal values, one's (own) life and professional priorities"6.

So the search for the meaning of life is assumed not as a teleological trajectory in which the right values of reference are indicated, but as an exercise that allows the subject to stop and think about things that he had not considered and that can be addressed in a critical and problematic way, in full agreement with the transformative vision of learning developed by Mezirow. The need to stop and reflect is manifested above all when in personal life problematic situations occur: these are Mezirow's existential dilemmas which require to assume positions that may determine a change, and thus allow to actualize the personal potential meaning of life.

Bernaud believes that it is possible to accompain this discounting process to allow the development of self-government which, according to the author, is based on five fundamental point, summarized below:

- a better understanding of oneself and others based on the analysis of one's own values in order to define priorities for the future

- development of the capacity to act to promote the change using personal and environmental resources

\footnotetext{
${ }^{4}$ Bernaud J.L. (2015). Psicologia dell'accompagnamento. Il senso della vita e del lavoro nell'orientamento professionale. Trento: Erikson; pp 47-49 (ndr: translation by the author of the paper)

${ }^{5}$ Ibidem; $\mathrm{p} 51$ (ndr: translation by the author of the paper)

${ }^{6}$ Ibidem; p 53 - (ndr: translation by the author of the paper)
} 
- a reflection on the environments, the interactions and the actions to be taken to get closer to one's (own) art of living

- a development of permanent reflection to face an uncertain world, to get rid of false beliefs, favoring meaning-making decisions

- an activity that values the interest for others and for humanity.

Moreover, referring to Mancinelli (2008), in the theoretical design of the Notebook on the Meaning of Life, we wanted to give importance to the imagination, powerful and vital human faculty that allows us to represent cultural objects and non-existent realities, or not yet existing, and which is at the basis not only of the existential planning, but of the scientific research itself. The educational methods and the teaching tools to encourage the exercise of reflection in training are many (Batini, 2005a, 2005b), but most of them share the idea that narrative dimension improve the semantic and diachronic organization of reflection's objects. The authors of this work believe that the electronic portfolio (ePortfolio, eP) is a particularly suitable tool to testify the training stages reached by a subject and at the same time the followed path; moreover, eP is a flexible and dynamic tool that allows subjects to easily prepare a collection of informative data immediately accessible by any electronic support able to connect to the web (La Rocca, 2015).In the previously researches carried out by the authors of this work, the need to direct the subjects to the construction of a mixed eP has emerged. Therefore some of the pages composing the eP are processed freely by the subject according to his/her originality and have the purpose of highlighting skills, knowledge, competences possessed and considered worthy of consideration.

Some other pages are made up following defined and structured trajectories, aimed at bringing out reflections according to the sense of the educational project and the studies that corroborate it. The Notebook on the Sense of Life has to be included in this second type of eP page: the subjects are invited to build a page of eP following the indications and the exercises proposed, about which we will offer a brief summary in the next paragraph.

\subsection{The Notebook to Reflect on the Sense of Life: The Tool}

A descriptive summary of the tool is below; the tool is structured in six pages. Due to the limited space, the exercises, operating plans and observation grids have not been fully reported. The contents of the pages reported in this work are directed to the operator / educator who supports the subject in compiling the tool. Pages 2-3-4-5 were built on the basis of the tools developed by Jean-Luc Bernaud in the second part of his book "Psychology of accompaniment". The meaning of life and work in vocational guidance. Page 1 has been elaborated assuming the solicitations contained in the text of Maria Rosaria Mancinelli "Techniques of imagination for the orientation and the formation" and by referring to the Zimbardo \& Boyd's ZTPI ${ }^{7}$. Page 6 has been inserted in order to facilitate the sharing of the reflection elaborated by each person.

\section{Page 1: The imagined future}

- Session goals: establishing a playful and confidential approach; solicitying the description of the imagined future to leverage on the intrinsic motivation for personal training - not starting from the request for a description of the past.

- Methodology: a) use of multimedia tools and materials to allow the subject to build his/her image of the future, in order to show it to himself and to the operator; b) dialogue set on themes taken from the ZTPI (Zimbardo \& Boyd); c) assignment of the task for the next session (collect further material that is related to the future imagined to enrich the elaborate image)

- Timing of the session: two meetings of two hours each; the execution of the exercises must be carried out with the support of the teacher/operator, in an atmosphere of dialogue and availability. The teacher /operator observes the event systematically using (using) a special observation grid.

\footnotetext{
${ }^{7}$ All the mentioned texts are included in the bibliography 


\section{Page 2: Finding the meaning}

- Session goals: delivery of page 1; description of the procedures in which the sessions take place, specifying that the sessions are not of a psychotherapeutic nature and are not skills development plans, but aim at developing self-awareness, self-assessment and at recognition of the meaning attributed to life and work.

- Methodology: a) exercise on the eulogy (also funerary) of a person or character considered exemplary; b) exercise on the description of a piece of art (various kinds) and on the reflections arising from it; c) assignment of the task for the next session (bring a meaningful / representative image of one's own culture, ideals, values, etc .., complete the exercises also with the help of multimedia materials).

- Timing of the session: two meetings of two hours each; the execution of the exercises must be carried out with the support of the teacher / operator, in an atmosphere of dialogue and availability. The teacher / operator observes the event systematically using a special observation grid.

\section{Page 3: The analysis of the values}

- Session goals: supporting the person in the identification of his/her reference values.

- Methodology: a) exercise on the identification and analysis of one's own values; b) reflection activity on the weight that the values have in one's own life; c) exercises that help to place one's values in the perspective of professional development and life; d) assignment of the task for the next session (collecting additional materials related to the field of values)

- Timing of the session: two meetings of two hours each; the execution of the exercises must be carried out with the support of the teacher / operator, in a climate of dialogue and availability. The teacher / operator observes the event systematically using a special observation grid.

\section{Page 4: The narrative of personal, educational and professional life paths}

- Session goals: development of a planning strategy.

- Methodology: a) indication of the positive and negative events experienced in the personal, training and professional fields using the appropriate sheet; b) projection in the future of events just experienced for identify potential outlets; c) assignment of the task for the next session (complete the exercises also with the help of multimedia materials).

- Timing of the session: two meetings of two hours each; the execution of the exercises must be carried out with the support of the teacher / operator, in an atmosphere of dialogue and availability. The teacher / operator observes the event systematically using a special observation grid.

\section{Page 5: The development of the art of living}

- Session goals: developing a conscious reflection on the conditions of existence and on achieving a balance; identifying the priorities in life and work.

- Methodology: a) providing the appropriate sheet and the guided questions (adapted from Bernaud 2015, pp. 184-186); b) dialogue about the results and comment.

- Timing of the session: two meetings of two hours each; the execution of the exercises must be carried out with the support of the teacher / operator, in an atmosphere of dialogue and availability. The teacher / operator observes the event systematically using a special observation grid.

\section{Page 6: Sharing}

- Session goals: developing a sense of belonging and relationship.

- Methodology: sharing the eP - the Notebook to reflect on the Sense of Life page - in small groups.

- Timing of the session: two meetings of two hours each; the execution of the activity must be carried out with the support of the teacher / operator, in an atmosphere of dialogue and 
availability. The operator will convene the students who have compiled the eP personal page The Notebook to reflect on the Sense of Life - in three, four people groups, chosen according to a criterion that must be explained and shared with the research group; the criterion could be either that of the greatest difference possible, in relation to the place of origin and culture, or the major similarities found in individual pages. In the first case, transversal provoking each other is favored, in the second case the development of the proximity between the subjects is expanded. The teacher / operator organizes the meetings in order to favor the circulation of the contributions included in each eP page and observes the event systematically using a special observation grid.

\section{Closing Note}

Currently, the Notebook to reflect on the Sense of Life is being tested in the Einaudi Professional Institute (RM), which participates in the CREI project, and whose student population appears strongly characterized by the presence of young people of first and second immigrant generation and young people having various kind of problems (social, cultural, linguistic, etc). This first administration of the instrument is a pilot experience, in order to allow its development and operational verifiability; the results will be shown in a future publication.

\section{REFERENCE}

[1] Allen R.T. (1991) The Meaning of Life and Education. in Journal of Philosophy of Education, Vol. 25, No. 1,1991

[2] Aviram, A. (2010) Navigating Through the Storm: Reinventing Education for Postmodern Democracies (Rotterdam, Sense Publishers)

[3] Batini F. (2005a) (a cura di) Manuale per orientatori. Metodi e scenari per l'empowerment personale e professionale. Trento: Erickson

[4] Batini F., Del Sarto G. (2005b) Narrazioni di narrazioni. Orientamento narrativo e progetto di vita. Trento: Erickson

[5] Barrett, H. (2003) Presentation at First International Conference on the e-Portfolio, Poiters, France, October 9, 2003. http://electronicportfolios.org/portfolios/eifel.pdf

[6] Barrett H. C. \& Wilkerson J. (2004). Conflicting Paradigms in Electronic Portfolio. Approaches Choosing an Electronic Portfolio Strategy that Matches your Conceptual Framework. http://electronic portfolios.org/systems/paradigms.html

[7] Bernaud J.L. (2015). Psicologia dell'accompagnamento. Il senso della vita e del lavoro nell'orientamento professionale. Trento: Erikson

[8] Bruner J. (1992). La ricerca del significato. Torino: Bollati Boringhieri

[9] Dewey J. (1938). Experience and Education. NY: Collier Boooks. Tr.it. Esperienza e educazione, (1949). Firenze: La Nuova Italia

[10] De Ruyter, D. J. (2002). The Right to Meaningful Education: The Role of Values and Beliefs', Journal of Beliefs \& Values, 23.1, pp. 33-42.

[11] Domenici G. (2009). Manuale dell'orientamento e della didattica modulare. Bari: Laterza

[12] Guichard J., Huteau M. (2003). Psicologia dell'orientamento professionale. Milano: Raffaello Cortina Editore

[13] Huang Jeff J.S., Yang Stephen J.H., Chiang Poky Y.F., Tzeng Luis S.Y., (2012) Building an e-portfolio learning model: Goal orientation and metacognitive strategies. Knowledge Management \& E-Learning: $A n$ International Journal, Vol.4, No.1. http://www.kmel-journal.org/ojs/index.php/online-publication/article /viewFile/163/131

[14] La Rocca C. (2015). "ePortfolio: l'uso di ambienti online per favorire l'orientamento in itinere nel percorso universitario". Giornale Italiano Della Ricerca Educativa, Anno VIII, Vol. 14, pp 157-174

[15] Mancinelli M.R. (2008). Tecniche d'immaginazione per l'orientamento e la formazione. Milano: Franco Angeli

[16] Margottini M, (2017). Applicazione di strumenti per l'autovalutazione di strategie di apprendimento e prospettiva temporale in ambito universitario, Journal of Educational, Cultural And PsychologicalStudies, Anno VIII, Vol. 15, pp. 229-251. Milano: Edizioni Universitarie di Lettere, Economia Diritto

[17] Mezirow, J. (2003). Apprendimento e trasformazione. Il significato dell'esperienza e il valore della riflessione nell'apprendimento degli adulti. Milano: Raffaello Cortina Editore

[18] Mezirow, J. (1999). Transformation Theory - Postmodern Issues. Kansas State University Libraries New Prairie Press. Adult Education Research Conference. Conference Proceedings (DeKalb, IL) 
[19] Pellerey M. (2004). Le competenze individuali e il portfolio, Milano, Etas scuola

[20] Pellerey M. (2007). Apprendimento e trasferimento di competenze professionali. In Orientare l'orientamento, Roma, Isfol, 305-323.

[21] Peters, R. S. (1973) Farewell to Aims? The London Educational Review, 2.3, pp. 1-4

[22] Pitts Wesley \&Ruggirello Rachel (2012) Using the e-Portfolio to Document and Evaluate Growth in Reflective Practice: The Development and Application of a Conceptual Framework. International Journal of ePortfolio 2012, Volume 2, Number 1, 49-74. ISSN: 2157-622X. http://www.theijep.com

[23] Schinkel A., De Ruyter D.J. \&Aviram A. (2016). Education and Life's Meaning, Journal of Philosophy of Education, Vol. 50, No. 3, 2016

[24] White, J. (2009) Education and a Meaningful Life, Oxford Review of Education, 35.4, pp. 423-435.

[25] Zimbardo, P. G., \&Boyd, J. N. (1999). Putting time in perspective: A valid, reliable individual-differences metric. Journal ofPersonality and Social psychology, 77, 1271-1288.

\section{AUTHOR'S BIOGRAPHY}

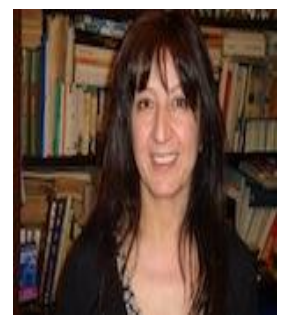

Concetta La Rocca is Researcher - PhD of "General Didactic" and Lecturer in the Doctoral School in "Educational and Social Theory and Research" at the Department of Education Sciences, Roma Tre University. She is a member of the SIRD (Italian Society of Didactical Research) and SIPED (Italian Society of Pedagogy). She also is a member of the Board of a University IInd Level Masters. La Rocca was and is employed in many empirical researches on questions related to e-learning, in particular, about evaluation, feedback and tutoring. Recently she has designed and realized the construction of an e. Portfolio at University. She has participated in several research projects, including two PRINs (Research Project of National Interest). Since 2003 she is member of the Organizational and Designing Committee of the Degree Course FAD. She has participated with his own scientific reports in several national and international Conferences and she is the author of some publications, including monographic texts, essays, scientific papers and multimedia products.

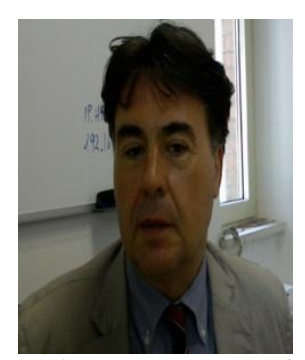

Massimo Margottini is Associate Professor of "General Didactics" and Lecturer in the Doctoral School in "Educational and Social Theory and Research" at the Department of Education Sciences, Roma Tre University. He is Director of the CAFIS (University Center for the Training of High School Teachers), member of the Board of Directors of the Roma Tre Education Foundation. From 2009 to 2016, he has been Rector's Delegate for Guidance Policies of the Roma Tre University, member of the Board of Directors and of the strategic scientific committee of the Inter-university Consortium AlmaLaurea (www.almalaurea.it). $\mathrm{He}$ is a member of the SIRD (Italian Society of Didactic Research), of which he was Secretary in the three-year period 2006/2008, and of the SIPED (Italian Society of Pedagogy). He carries out research on the themes of scholastic and professional orientation and on the integrated use of ICT in the organization of teaching. He has participated with his own scientific reports in several national and international Conferences and he is the author of numerous publications, including monographs, essays, articles and multimedia products.

Citation: Concetta La Rocca, Massimo Margottini. "The Notebook to Reflect on the Meaning of Life: A Page Inside the EPortfolio". International Journal of Humanities Social Sciences and Education (IJHSSE), vol 5, no. 6, 2018, pp. 73-80. doi: http://dx.doi.org/10.20431/2349-0381.0506010.

Copyright: (C) 2018 Authors. This is an open-access article distributed under the terms of the Creative Commons Attribution License, which permits unrestricted use, distribution, and reproduction in any medium, provided the original author and source are credited. 